\title{
Estrogen Regulation of the Expression of Pain Factor NGF in Rat Chondrocytes
}

This article was published in the following Dove Press journal:

Journal of Pain Research

\author{
Xiushuai Shang ${ }^{1,2}$ \\ Liaoran Zhang ${ }^{2}$ \\ Rilong Jin' \\ Hu Yang' \\ Hairong Tao ${ }^{2}$ \\ 'Department of Orthopedics Surgery, \\ The First Affiliated Hospital, Zhejiang \\ University School of Medicine, Hangzhou, \\ People's Republic of China; ${ }^{2}$ Shanghai Key \\ Laboratory of Orthopaedic Implant, \\ Department of Orthopaedic Surgery, \\ Shanghai Ninth People's Hospital, \\ Shanghai Jiao Tong University School of \\ Medicine, Shanghai, People's Republic of \\ China
}

Correspondence: Hairong Tao Shanghai Key Laboratory of Orthopaedic Implants, Department of Orthopaedic Surgery, Shanghai Ninth People's Hospital, Shanghai JiaoTong University School of Medicine, No. 639 Zhizaoju Road, Shanghai, 2000II, People's Republic of China

Tel +86-1376/22/256

Email doctorthr@163.com
Objective: Pain is the main symptom of osteoarthritis (OA). Nerve growth factor (NGF) plays a crucial role in the generation of OA pain. And estrogen-alone used resulted in a sustained joint pain reduction in postmenopausal women. So we aim to find whether estrogen alters chondrocytes' NGF level, affecting OA pain.

Methods: Primary chondrocytes and cartilage explants isolated from Sprague Dawley rat knees were cultured with physiological concentrations of estrogen $(17 \beta$-Estradiol $\geq 98 \%$, E2), Estrogen Receptor $\alpha(\mathrm{ER} \alpha)$ inhibitor and stimulants. Then, chondrocytes NGF mRNA expression and protein release were analyzed by a quantitative real-time polymerase chain reaction (qPCR) and enzyme-linked immunosorbent assay (ELISA) respectively. Additionally, cultures were pre-incubated with MEK-ERK inhibitor to identify the signaling pathway that estrogen alters NGF mRNA and protein levels.

Results: We found that chondrocytes NGF expression and release were decreased by E2. E2 also reduced chondrocytes IL-1 $\beta$-stimulated or TGF- $\beta 1$-stimulated NGF expression. Phosphorylated extracellular signal-regulated kinasep1/2 (p-ERK1/2) signals were detected stronger than the control group by Western Blotting (WB). When we cultured chondrocytes with PD98059 (MEK-ERK inhibitor, PD), NGF mRNA expression was added to $1.41 \mathrm{Ct}$ (2.07 \pm 0.1 fold).

Conclusion: We showed that E2 reduces chondrocytes NGF expression significantly, even after stimulation by TGF- $\beta 1$ or IL- $1 \beta$. MEK-ERK signaling is involved in this process.

Keywords: osteoarthritis, pain, estrogens, nerve growth factor

\section{Introduction}

Osteoarthritis (OA) is a degenerative joint disease, characterized by articular cartilage loss, subchondral bone remodeling, and osteophyte formation with or without synovitis. ${ }^{1}$ Pain is the main symptom of OA resulting in low life quality and even disability. Global Burden of Disease Study 2017 told us the years lived with disability (YLD) rate of OA was 118.8 per 100,000 , increased by $9.6 \%$ since 1990. ${ }^{2}$ And treatments limited to Non-steroidal anti-inflammatory drugs(NSAIDs), physical therapy, steroid, and ultimately, surgery when developing into severe disability. ${ }^{3}$ In recent years, NGF's role in mediating pain has been identified. Inhibitors targeting NGF to relieve OA pain were developed, applied to clinical trials and obtained clinically significant effect. ${ }^{4-6}$

Nerve growth factor (NGF) is a member of the neurotrophic factors family, which was regarded as a promoter of sensory neuron survival, axonal growth and neurotransmission initially. ${ }^{7}$ But later, its crucial role in nociceptor development and pain generation was made out. Exposure to NGF leads to hyperalgesia and 
expression of substance $\mathrm{P}$ and pain receptor TRPV1. ${ }^{5,8}$ NGF concentration of synovial fluid not only increased in animal models ${ }^{9}$ but also in OA patients. ${ }^{10}$ More importantly, NGF expression of chondrocytes ${ }^{11}$ and synovial tissue $^{12}$ was discovered. Stimulation of TGF- $\beta 1,{ }^{13}$ IL$1^{11,13}$ and damaged cartilage ${ }^{14}$ would enhance chondrocytes NGF expression, which made us think that articular cartilage is one of the main sources of NGF in OA. And inhibiting NGF in clinical Phase III trials is efficient in relieving OA joint pain. ${ }^{15,16}$ Based on the efficiency of blocking $\mathrm{NGF}^{17}$ down-regulating chondrocytes NGF expression may be another new method to block pain.

In addition, a randomized trial suggested that postmenopausal women using estrogen alone obtained a modest but sustained reduction in OA joint pain. ${ }^{18}$ By reviewing previous articles, ${ }^{19-21}$ we found there are sex differences from prevalence to interventional results of $\mathrm{OA}$ or rheumatoid arthritis. And the correlation between estrogen and OA symptoms was reported. ${ }^{22-24}$ However, the mechanism by which estrogen reduces OA pain is undiscovered. Actually, estrogen down-regulated NGF or trkA (a transmembrane tyrosine kinase, high-affinity NGF receptor) in nerve tissue and its target organ have been reported early. So we hypothesize that estrogen can reduce chondrocytes NGF expression leading to OA pain relief.

In this study, our goals were to determine whether estrogen can reduce chondrocytes NGF expression, even when exposed to stimulants TGF- $\beta 1$ and IL- $1 \beta$, then to identify potential mechanisms involved.

\section{Materials and Methods}

All animal experiments in this study have been approved and monitored by the Animal Care Committee of Shanghai Jiao Tong University School of Medicine. All experiments were conducted based on the state guidelines from the Ministry of Science and Technology of China.

\section{Rat Primary Chondrocytes and Cartilage Explants}

Non-calcified cartilage layers were obtained by scalpel from 8-week old female rats' (Silaike, Shanghai, China) knees joints within one hour after Euthanasia. Then, the cartilage was cut into approximately $1 \mathrm{~mm}$ pieces and treated with $0.25 \%$ trypsin (Gibco, China) for $10 \mathrm{~min}$, followed by treatment with $0.2 \%$ collagenase II (SigmaAldrich-Aldrich, China), in DMEM/F12 (GE Healthcare Life Sciences, China) for $5 \mathrm{~h}$. The suspension was filtered through a $70-\mu \mathrm{m}$ cell strainer (Sigma-Aldrich-Aldrich, China), washed in DMEM/F12, counted, and seeded at a density of $1 \times 10^{5}$ cells per $\mathrm{cm}^{2}$. Chondrocytes would be cultured for 1 week in DMEM/F12 medium with $10 \%$ FCS (Gibco, China) under $37^{\circ} \mathrm{C}$ and $5 \% \mathrm{CO}_{2}$. After that, chondrocytes' phenotype was confirmed by toluidine blue staining of glycosaminoglycan and type II collagen's immunocytochemical staining. For cartilage explants, $3 \mathrm{~mm}$ punches were used for the purpose of generating equal size, and then explants were randomly distributed over the different conditions, three explants per condition per rat.

\section{Experiments}

According to the methods described in Ref. 13, cells or explants were serum-starved overnight prior to stimulation. Chondrocyte cultures were supplemented with physiological concentrations estrogen (synthetic; 0.1nM; Sigma-Aldrich, shanghai, China), and with or without estrogen receptor inhibitors-ERainhibitor MPP $^{25}$ (20uM; Sigma-Aldrich, shanghai, China) and ER $\beta$ inhibitor PHTPP $^{26,27}$ (20uM; Sigma-Aldrich, shanghai, China). Later, recombinant human TGF- $\beta 1 \quad(10 \mathrm{ng} / \mathrm{mL}$; Peprotech, shanghai, China) and IL-1 $\beta$ (1 ng/mL; Peprotech, shanghai, China) were added into the culture medium, respectively. Then, E2 $(1 \mathrm{nM})$ was added into the training systems including TGF- $\beta 1$ or IL- $1 \beta$. DMSO (Sigma-Aldrich, shanghai, China) was used as vehicle control in the experiments. And chondrocytes were preincubated with inhibitors for $0.5 \mathrm{~h}$ prior to the addition of E2. Estrogen was added $30 \mathrm{~min}$ prior to TGF- $\beta 1$ and IL$1 \beta$. Cultures were maintained for $24 \mathrm{~h}$, at which point medium was harvested for ELISA, chondrocytes were harvested for qPCR or WB.

\section{RNA Isolation and $q P C R$}

Total RNA was isolated from chondrocytes and cartilage explants as previously described ${ }^{11,13}$ using TRI Reagent (Thermo Fisher Scientific, China) according to the manufacturer's protocol. RNA concentration was measured using a Nanodrop 2000 (Thermo Fisher Scientific, USA), and cDNA was prepared with an RNA reverse transcription kit (Roche, China) according to the manufacturer's protocol.

Gene expression was measured by validated cDNAspecific primers (Table 1; Shenggong, Shanghai, China) in a quantitative real-time polymerase chain reaction (qPCR) using SYBR green master mix (Roche, China), 
Table I Primers for NGF

\begin{tabular}{|l|l|l|}
\hline Gene & Forward $\mathbf{5}^{\prime} \rightarrow \mathbf{3} \mathbf{3}^{\prime}$ & Reverse 5' $\mathbf{3} \mathbf{3}$ \\
\hline Rat GAPDH & ACCACAGTCCATGCCATCAC & TCCACCACCCTGTTGCTGTA \\
Rat NGF & GAGCCCCGAATCCTGTAGA & AGCCTGTTTGTCTGTTGT \\
\hline
\end{tabular}

Abbreviation: NGF, nerve growth factor.

with machine LC480 (Roche, China). The cDNA was diluted $10 \mathrm{ng} / \mu \mathrm{L}$ in DEPC water (Thermo Fisher Scientific, China), and $2 \mu \mathrm{L}$ was used in each $20 \mu \mathrm{L}$ reaction system. The protocol was: pre-incubation $10 \mathrm{~min}$ at $95^{\circ} \mathrm{C}$, followed by 40 cycles of: $15 \mathrm{~s}$ at $95^{\circ} \mathrm{C}$ and $1 \mathrm{~min}$ at $60^{\circ} \mathrm{C}$. Data is expressed as $-\Delta \Delta \mathrm{Ct}$ values corrected for GAPDH and controls with $2-\Delta \Delta \mathrm{Ct}$ methods.

\section{ELISA}

NGF concentration in the medium was measured using an ELISA kit (Sigma-Aldrich, USA) according to the manufacturer's instructions. The detection limit of NGF was 7.8 $\mathrm{pg} / \mathrm{mL}$ and the intra-assay coefficient of variation was $4.1 \%$. NGF concentrations were analyzed in duplicate at serial dilution (neat, 1:2, and 1:4, linearity of dilution is good) and were read against a standard curve.

\section{Western Blotting}

Cells were placed on ice and washed twice using icecold saline. Cells were then lysed using lysis buffer (Cell Signaling Technology, shanghai, China) containing protease inhibitor cocktail (Complete MINI, Roche, China). Cell lysates were rotated on ice for 4 cycles of 30 $\mathrm{s}$ rotating and 5 min rest, using a vortex. Samples were then centrifuged at $4{ }^{\circ} \mathrm{C}$ at $12,500 \mathrm{rpm}$ for $15 \mathrm{~min}$ and pellets were discarded. Protein concentration was measured using the BCA assay (Beyotime Biotechnology, shanghai, China). An equal amount of protein was loaded into the wells on an $8 \%$ bis-acrylamide gel, for SDS-PAGE. After electrophoresis, proteins were transferred to a polyvinylidene fluoride using the wet transfer $(2.5 \mathrm{~h}$ at $275 \mathrm{~mA})$. After overnight incubation at $4^{\circ} \mathrm{C}$ with 1:1000 anti-p-ERK (T202/Y204) (Cell signaling, USA), membranes were incubated with 1:10000 HRPlinked anti-Rabbit IgG (Cell Signaling Technology, shanghai, China) for $1 \mathrm{~h}$. Hereafter, enhanced chemiluminescence (ECL) using ECL plus kit (Beyotime Biotechnology, shanghai, China) was used to visualize the proteins. As a loading control, 1:10000 HRP-linked GAPDH (KANGCHEN) was used.

\section{Statistical Analysis}

Every experiment within this paper was independently repeated three times in order to verify the credibility of the results. Data are expressed as mean \pm standard error of the mean (SEM). For the experiments, statistical analysis was performed using Graphpad6 Prism software. Intergroup comparisons were performed with unpaired Student's $t$-test. Values with $\mathrm{p}<0.05$ were considered significant.

\section{Results}

\section{Estrogen Down-Regulates Rat Knee Cartilage Chondrocytes NGF Expression and Release via ER $\alpha$}

To investigate whether estrogen altered NGF expression in chondrocytes, we exposed rat primary chondrocytes to estrogen $(0.1 \mathrm{nM}$ to $0.1 \mu \mathrm{M}$, data not shown) for 12,24 , 48 or 72 hours. After 24 hours with $1 \mathrm{nM}$ estrogen, expression of NGF mRNA was significantly downregulated about $0.7 \mathrm{Ct}(0.55 \pm 0.13$ fold $)$ compared to controls (Figure 1A) as well as protein release (Figure 1B). To investigate whether estrogen acts through ER $\alpha$ alter NGF expression, we used a specific ER $\alpha$ inhibitor MPP $(20 \mu \mathrm{M})$ and a specific ER $\beta$ inhibitor PHTPP $(20 \mu \mathrm{M})$. In the ER $\alpha$ inhibitor-treated group, the downregulation was prevented, while in PHTPP-treated group not. Our data clearly showed that estrogen down-regulated expression of NGF (Figure 1C) and protein release (Figure 1D) by ER $\alpha$ in rat chondrocytes.

\section{Estrogen Decreases NGF Expression and Release in Rat Cartilage Explants via ER $\alpha$} Known from experience, intact cartilage responds differently from isolated chondrocytes. In order to mimic in vivo conditions, we utilized freshly isolated cartilage explants from healthy rat joints and exposed these to E2. Isolated explants were left untreated for $24 \mathrm{~h}$ to reach a state of equilibrium. Estrogen treatment down-regulated NGF expression and protein release through ER $\alpha$ (Figure 2). 
A

Rat chondrocytes

NGF/GAPDH mRNA expression

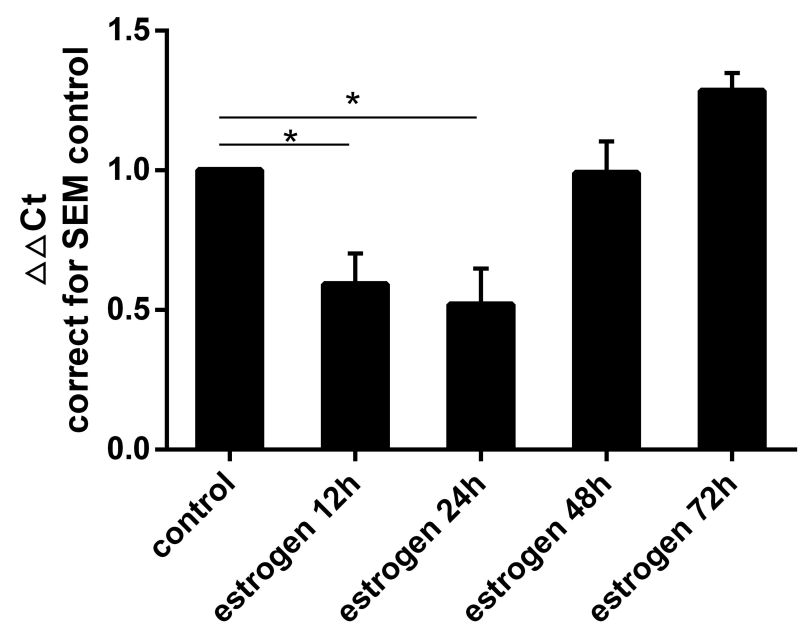

C

Rat chondrocytes

NGF/GAPDH mRNA expression

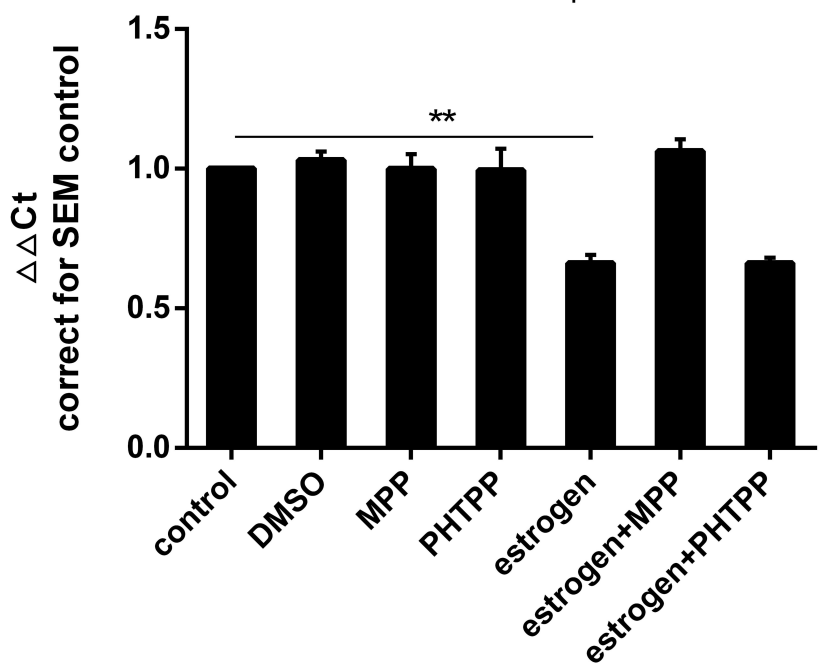

B

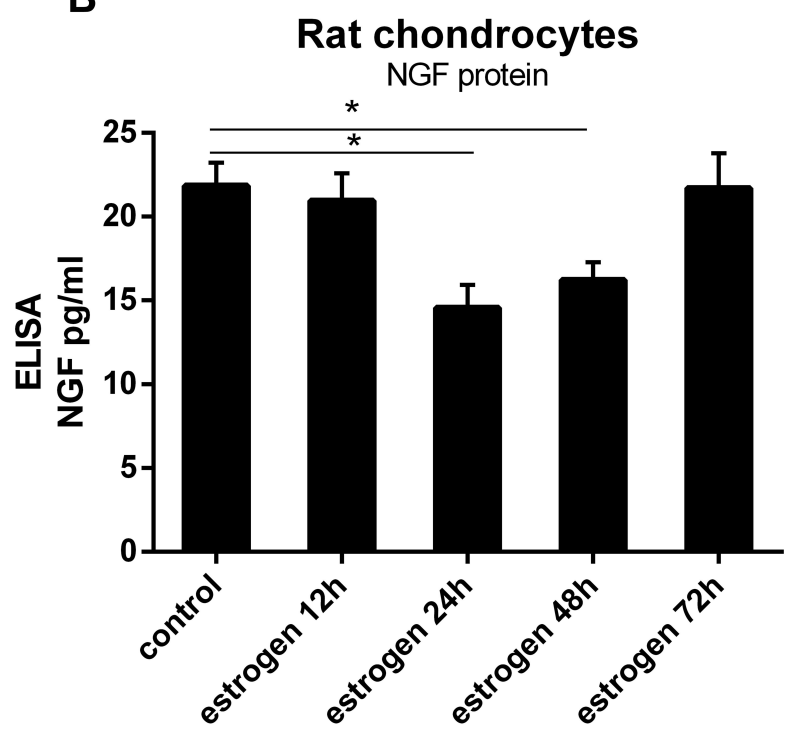

D

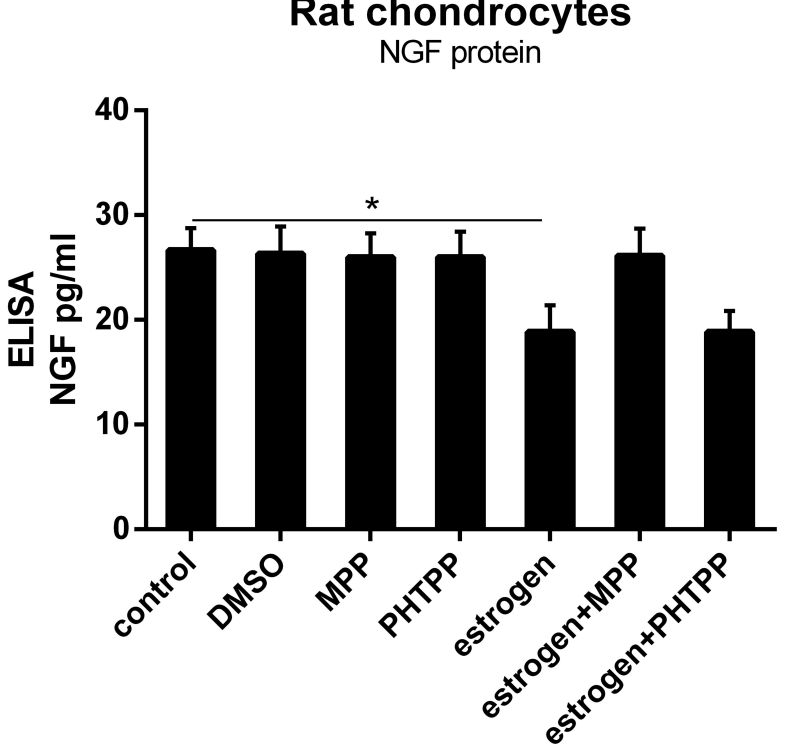

Figure I Estrogen downregulated rat chondrocytes NGF expression and release via ER $\alpha$. (A) Rat primary chondrocytes were exposed to estrogen at a dose of I nM for 0 , 12, 24, 48 or 72 hours. At 24 hours with I nM estrogen, expression of NGF mRNA was downregulated ( $0.7 \mathrm{Ct}$, $0.55 \pm 0.13$ fold) compared to the control. (B) Decrease in NGF protein levels were observed similarly to gene expression. (C) Rat primary chondrocytes were exposed to estrogen with or without ER inhibitors (MPP, PHTPP). Coincubation with MPP, thereby preventing estrogen-ER $\alpha$ signaling could prevent estrogen-decreased NGF mRNA expression, while with PHTPP was not. (D) Co-incubation with MPP prevented estrogen-decreased NGF protein release. All data were shown as mean \pm SEM from three independent experiments.

Notes: *P $<0.05, * * \mathrm{P}<0.01$.

Abbreviations: ELISA, enzyme-linked immunosorbent assay; NGF, nerve growth factor; MPP, a specific estrogen receptor $\alpha$ antagonist; PHTPP, a selective estrogen receptor $\beta$ antagonist.

\section{Estrogen Down-Regulate TGF-} $\beta$ I-Stimulated and IL-I $\beta$-Stimulated Rat Chondrocytes NGF mRNA Expression

\section{and Protein Release}

To identify whether TGF- $\beta 1$ induced NGF expression in chondrocytes, we exposed rat primary knee chondrocytes to different doses of TGF- $\beta 1(1,10$ or $20 \mathrm{ng} / \mathrm{mL})$ for $24 \mathrm{~h}$. This treatment led to a $1.1 \mathrm{Ct}, 2.13 \mathrm{Ct}, 2.19 \mathrm{Ct}(1.21 \pm 0.1$ fold, 4.56 \pm 0.4 fold, $4.83 \pm 0.1$ fold) increase, respectively, in mRNA expression compared to control (Figure 3A). The release of NGF from rat chondrocytes into the media was measured after TGF- $\beta 1$ stimulation (Figure 3B). A significant increase in mRNA and protein was seen after treatment 
A

Rat cartilage explants

NGF/GAPDH mRNA expression

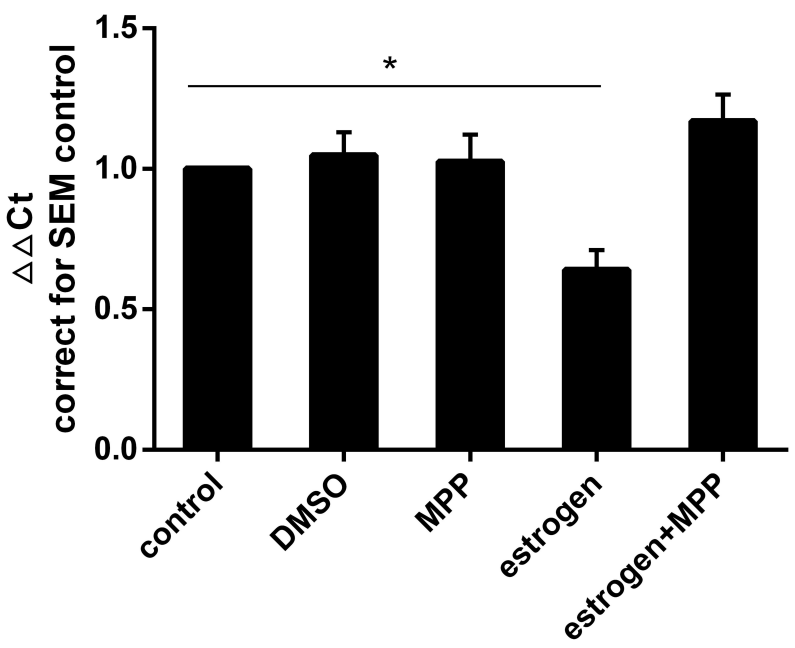

B

Rat cartilage explants

NGF protein

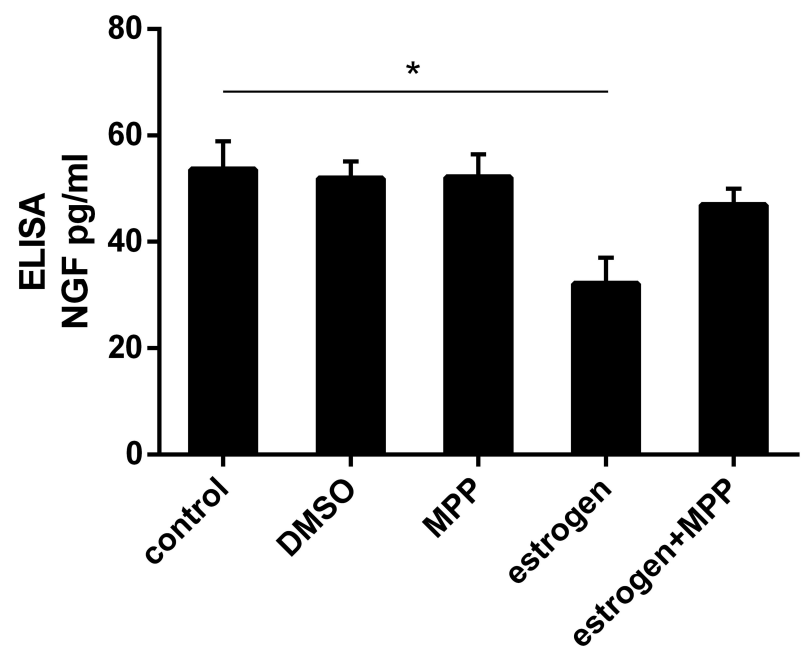

Figure 2 Estrogen decreased NGF expression and release in rat OA cartilage explants via ER $\alpha$. (A) Rat cartilage explants were stimulated with estrogen (InM) for 24 h,

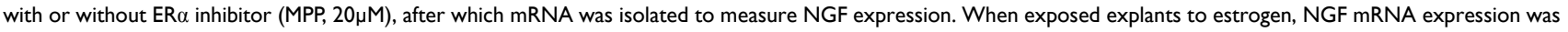
down-regulated about $0.8 \mathrm{Ct}(0.62 \pm 0.07$ fold), similarly to chondrocytes response. Decreased reaction disappeared after estrogen combined with MPP. (B) NGF protein measured by ELISA matched mRNA changes. All data were shown as mean \pm SEM from three independent experiments.

Note: $* \mathrm{P}<0.05$.

Abbreviations: OA, osteoarthritis; MPP, a specific estrogen receptor $\alpha$ antagonist; ELISA, enzyme-linked immunosorbent assay; NGF, nerve growth factor.

with $10 \mathrm{ng} / \mathrm{mL}$ TGF- $\beta 1$ as compared to unstimulated chondrocytes. Similarly, stimulation with IL-1 $\beta(0.1,1$ or $10 \mathrm{ng} /$ $\mathrm{mL}$ ) increased NGF mRNA expression (Figure 3C) and protein release (Figure 3D); 1 and $10 \mathrm{ng} / \mathrm{mL}$ induced an approximate increase $(42.67 \pm 4.31$ versus $25.72 \pm 2.59$, $45.58 \pm 2.28$ versus $25.72 \pm 2.59$ ).

Next, we investigated the effect of estrogen on TGF$\beta 1$-stimulated and IL- $1 \beta$-stimulated NGF expression in chondrocytes. Once again, TGF- $\beta 1$ and IL- $1 \beta$ elevated NGF expression and release as before. Estrogen combined with TGF- $\beta 1$ group, TGF- $\beta 1$ stimulation was partly inhibited (Figure 3E and F) by E2; the same phenomenon was observed in estrogen combined with IL-1 $\beta$ group (Figure 3E and F).

\section{ERKI/2 Was Involved in Chondrocytes NGF Metabolism Process}

Western blotting was used to determine whether p-ERK1/ 2 expression was altered in estrogen-treated group. The signal of $\mathrm{p}$-ERK1/2 was stronger than the non-treated group. The results of this analysis showed that the expression of p-ERK1/2 was 1.6 fold in the control group. It indicated that the quantity of $\mathrm{p}$-ERK $1 / 2$ from E2 group was significantly greater than from control group ( $\mathrm{P}=0.0084$, Figure 4B). When MEK-ERK signaling was inhibited by $20 \mu \mathrm{M}$ PD98059 (PD), we found a difference in p-ERK expression between the estrogen group and control group (Figure 4A and B). NGF mRNA estrogen-dependent downregulation was partly inhibited when exposed to PD. Chondrocytes NGF expression in cultured with PD increased $1.41 \mathrm{Ct}(2.07 \pm 0.1$ fold $)$ than non-treated (Figure 4C and D).

\section{Discussion}

Pain is one of the main symptoms of OA. Evidence suggests that NGF is a potential target for controlling OA pain. ${ }^{4,17}$ Favorable effects ${ }^{18,28,29}$ on relationships between estrogen and OA symptoms have been reported. In this paper, we showed that E2 reduces chondrocytes NGF expression significantly, even after stimulation by TGF$\beta 1$ or IL-1 $\beta$. MEK-ERK signaling is involved in this process.

At first, we showed that E2 down-regulated chondrocytes endogenous basal NGF expression and release in a time-dependent manner by ER $\alpha$. Evidence that supported estrogen had positive pain relief effects on patients ${ }^{18,30}$ and animals ${ }^{31}$ was reported previously. Chondrocytes could express NGF, ${ }^{14}$ and NGF/TrkA-induced axonal outgrowth in OA models was also investigated. ${ }^{32,33}$ Years ago, they had found the phenomenon that the regulation of NGF by estrogen in the rat. In the rat hippocampus, 
A

Rat chondrocytes

NGF/GAPDH mRNA expression

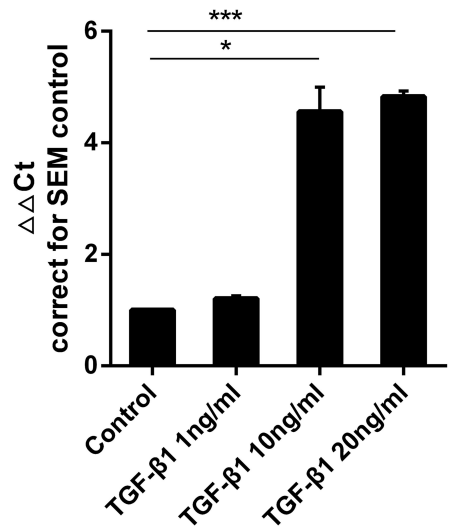

C

Rat chondrocytes NGF/GAPDH mRNA expression

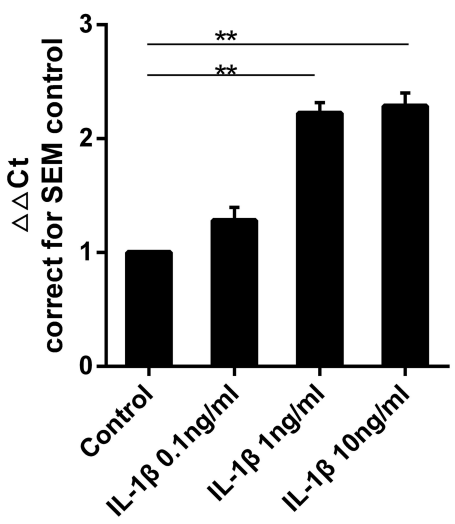

E

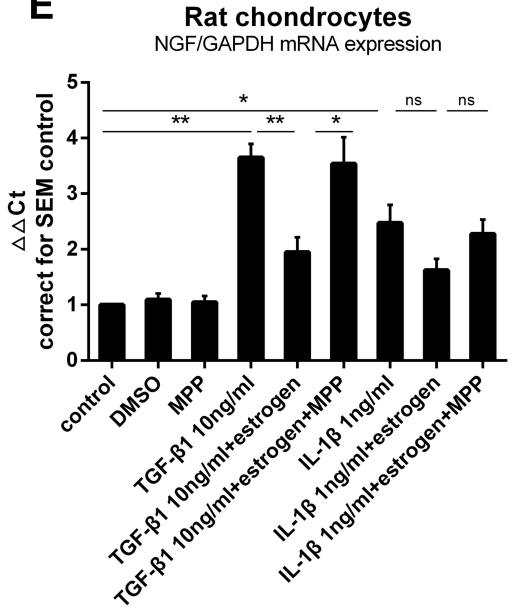

B Rat chondrocytes NGF protein

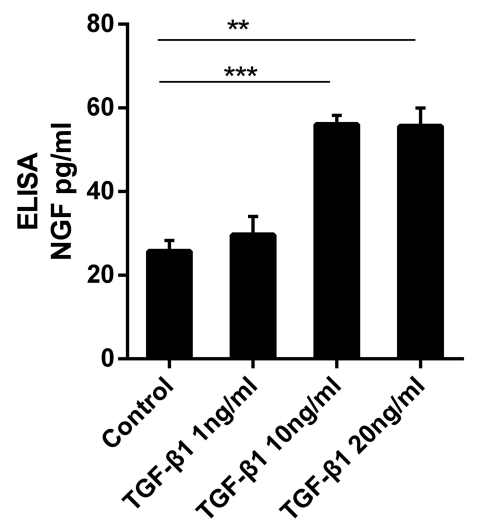

D Rat chondrocytes NGF protein

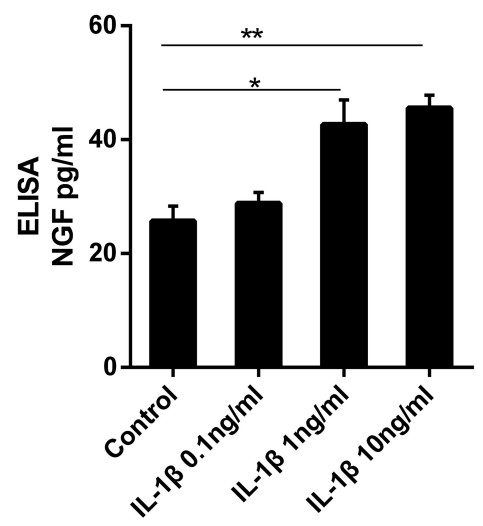

F Rat chondrocytes

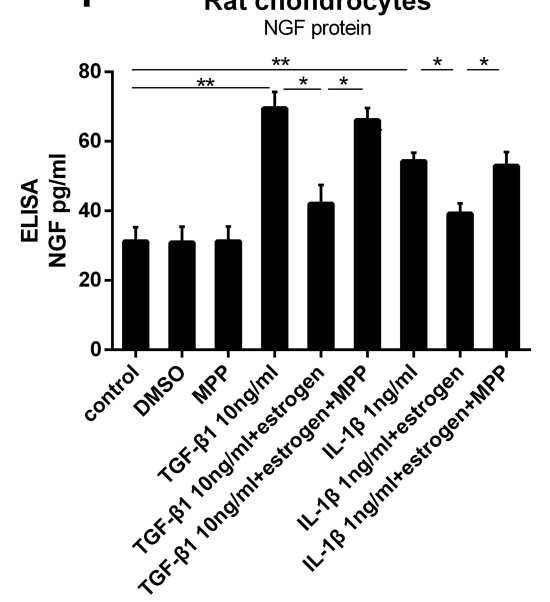

Figure 3 Estrogen down-regulate TGF- $\beta$ I-stimulated and IL-I $\beta$-stimulated rat chondrocytes NGF mRNA expression and protein release. (A) Rat chondrocytes were stimulated for 24 hours with increasing concentrations of TGF- $\beta \mathrm{I}(\mathrm{I}, 10$ and $20 \mathrm{ng} / \mathrm{mL}$ ), and NGF mRNA expression was measured by quantitative qPCR. (B) NGF protein release was measured by ELISA. (C) Rat chondrocytes were stimulated for 24 hours with increasing concentrations of IL-I $\beta$ (0.I, I and I0 ng/mL), and NGF mRNA expression was measured by quantitative qPCR. (D) NGF protein release was measured by ELISA. (E) TGF- $\beta$ I and IL-I $\beta$ were added, respectively, into media with estrogen, with or without MPP. Estrogen almost suppressed TGF- $\beta$ I and IL-I $\beta$ stimulated NGF mRNA expression. When cultured chondrocytes with estrogen, MPP, and TGF- $\beta$ I/LL$I \beta$, MPP resulted in estrogen-decreased phenomenon disappeared. (F) Co-incubated media were harvested and NGF protein was measured by ELISA. NGF protein levels paralleled with mRNA expression. All data were shown as mean \pm SEM from three independent experiments.

Notes: $* \mathrm{P}<0.05, * * \mathrm{P}<0.01, * * * \mathrm{P}<0.001$.

Abbreviations: NGF, nerve growth factor; qPCR, quantitative real-time polymerase chain reaction; ELISA, enzyme-linked immunosorbent assay. 
A

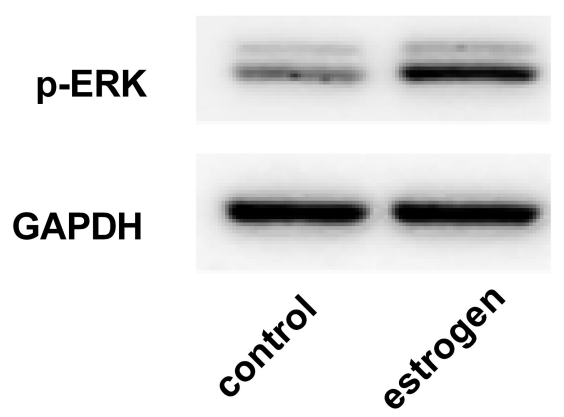

C

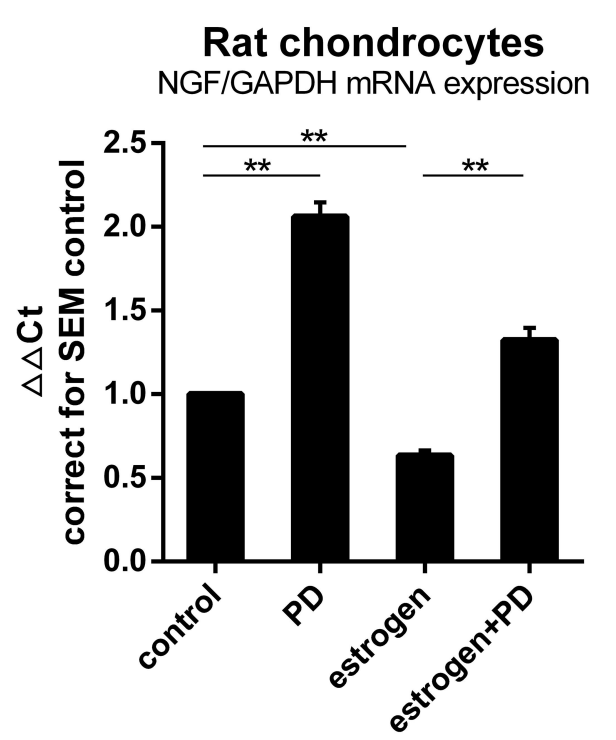

B

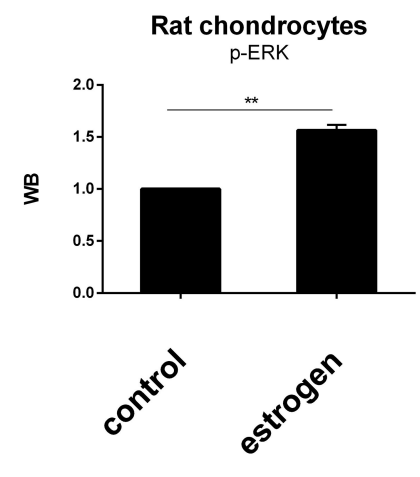

D

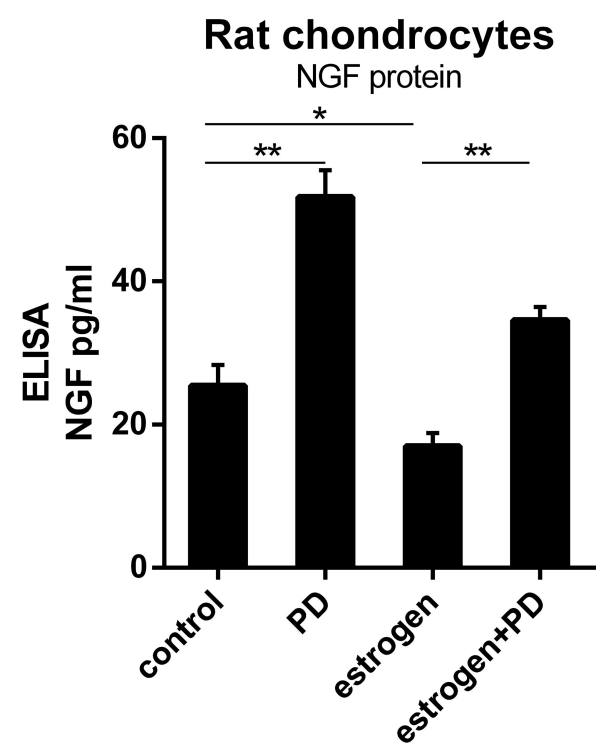

Figure 4 ERKI/2 was involved in the process of estrogen down-regulating NGF expression and release. (A) Protein was isolated from estrogen-treated chondrocytes, and p-ERK content was analyzed by WB, emerging a higher level than non-treated group. (B) WB results were quantified and presented in column graph style. Difference between two groups were seen clearly. (C) NGF mRNA expression in cultured with PD increased to I.4ICt (2.07 \pm 0.1 fold) than non-treated. Estrogen-decreased NGF level was inhibited by PD. (D) NGF protein release paralleled with mRNA tendency. All data were shown as mean \pm SEM from three independent experiments. Notes: *P $<0.05$, **P $<0.01$.

Abbreviations: ELISA, enzyme-linked immunosorbent assay; NGF, nerve growth factor; WB, Western blotting; PD, PD98059.

estrogen replacement resulted in NGF mRNA drop. ${ }^{34}$ In dorsal root ganglion neurons, levels of NGF and TrkA were also reduced with long-term estrogen replacement. ${ }^{35}$

Additionally, estrogen can regulate chondrocytes metabolism. $^{36,37}$ While the results clearly showed that NGF level was being down-regulated by E2, it was possible that either synthesis of the transcripts had been attenuated or protein degradation had been stimulated, or some combination of both. The blockade of the neurotrophic response to E2 by ER $\alpha$ suggested that gene transcriptional activation was involved. Our results matched other studies that mentioned above and encouraged us to perform further experiments. So far, within our knowledge, we may be the first team to describe the regulation of NGF by estrogen in chondrocytes. It may provide a new therapy for relieving OA pain.

As the chondrocytes in vivo may response differently from isolated chondrocytes, we isolated freshly cartilage explants to mimic the internal environments of the joint. We observed a decrease in NGF mRNA expression and protein release when exposed cartilage explants to E2, similar to chondrocytes' response. Similar studies have been reported by Pecchi et $\mathrm{al}^{11}$ in newborn mouse cartilage and by Blaney Davidson et $\mathrm{al}^{13}$ in human OA cartilage. In these studies, parallel results of isolated chondrocytes and fresh explants in response to the stimulus provided convinced outcomes. 
IL-1 $\beta$ and TGF- $\beta 1$ can increase NGF expression and release in a dose-dependent manner in rat primary knee chondrocytes. Elevated TGF- $\beta 1^{38}$ and IL- $1 \beta^{14}$ were detected in OA patients' joints. IL-1 $\beta$ is well known as a pro-degradation cytokine that can enhance matrix metalloproteinase (MMP) synthesis. ${ }^{39}$ Now, it is also considered as a stimulus with a close relationship to OA pain. ${ }^{12,40}$ TGF- $\beta 1$ is stored in high amounts in articular cartilage and is released when the cartilage is damaged. ${ }^{41}$ Actually, in cell experiments, both of them can stimulate chondrocytes NGF expression, and TGF- $\beta 1$ is even more potent than IL$1 \beta .^{11,13}$ Our results further identified that there were no differences among species when compared to Iannone's study, which including murine, bovine and human chondrocytes.

When cultured chondrocytes with estrogen combined IL- $1 \beta$ or TGF- $\beta 1$, the IL- $1 \beta$-stimulated and TGF$\beta 1$-stimulated were partly decreased. It once again convinced us of the regulation of E2 to NGF. We thought that partial reduction rather than complete may result from stimulus' more potential up-regulation. This explained that estrogen use alone provided a modest but sustained joint pain reduction in postmenopausal women. ${ }^{18}$ As the process of NGF transcription was not clear now, we have no idea about the regulation that E2 interacted with NGF promoter. But we investigated and discussed the possible signal path in the regulation.

Estrogen has favorable effects on reducing pain, ${ }^{18,28,29}$ but no certain mechanisms have been identified. From others' work, we knew that ERK was involved in the NGF upstream ${ }^{42}$ and downstream ${ }^{33}$ pathways. So we investigated the role of MEK-ERK in chondrocyte NGF metabolism. Expectedly, we detected changes in p-ERK quantity when treated chondrocytes with estrogen. MEKERK involvement was identified by qPCR and ELISA analysis. This indicates an existing role for ERK1/2 in maintaining the basal level of NGF; estrogen may reduce NGF level via p-ERK1/2. This is similar to the result that estrogen can down-regulate NGF in rat hippocampus and sympathetic neurons. ${ }^{43,44}$ Genistein, a phytoestrogen, can affect mast cells through the inhibition of the ERK pathway. Our work indicates that ERK1/2 plays a role in NGF expression. The exact role needs to be investigated further in the future.

In this study, we confirmed that estrogen reduced NGF mRNA expression and protein release in rat primary chondrocytes via $E R \alpha$, and down-regulated NGF levels stimulated by TGF- $\beta 1$ and IL- $1 \beta$. However, we are not sure how
E2 interacts with the NGF promoter, and the certain mechanism remains still unclear. In $\mathrm{OA}$ joint, various factors, including TGF- $\beta 1$, IL- $1 \beta$, TNF- $\alpha$ and adipokines, exist simultaneously. The interactions that they interact with NGF deserve to be clarified. Finally, estrogen can modulate pain, both centrally and peripherally, ${ }^{45}$ with both NGF and trkA expression. ${ }^{35,46}$ The mechanism is exceedingly complex, which may need us to pay more attention to the interaction of estrogen and NGF.

In conclusion, we found that estrogen can down-regulate NGF levels via ER $\alpha$ in rat primary chondrocytes. TGF- $\beta 1$ and IL-1 $\beta$ can induce NGF expression and release in vitro. E2 also partly down-regulated TGF- $\beta 1 / \mathrm{IL}-1 \beta$-stimulated NGF mRNA levels and protein release. In addition, p-ERK1/2 may play a role in the mechanism that E2 regulates chondrocytes NGF expression. These may explain why estrogen use alone resulted in a modest but sustained reduction in the frequency of joint pain in postmenopausal women. In the future, NGF down-regulation may be applied to clinical to relieve OA joint pain.

\section{Acknowledgments}

We thank Prof. Dong Li for supporting chondrocytes phenotype identification. This work is funded by Shanghai Natural Science Foundation (19ZR1429200).

\section{Author Contributions}

All authors made substantial contributions to conception and design, acquisition of data, or analysis and interpretation of data; took part in drafting the article or revising it critically for important intellectual content; agreed to submit to the current journal; gave final approval of the version to be published; and agree to be accountable for all aspects of the work.

\section{Disclosure}

The authors report no conflicts of interest in this work.

\section{References}

1. Kolasinski SL, Neogi T, Hochberg MC, et al. 2019 American College of Rheumatology/Arthritis Foundation Guideline for the Management of Osteoarthritis of the Hand, Hip, and Knee. Arthritis Rheumatol. 2020;72(2):149-162. doi:10.1002/acr.24131

2. Safiri S, Kolahi AA, Smith E. Global, regional and national burden of osteoarthritis 1990-2017: a systematic analysis of the Global Burden of Disease Study 2017. Ann Rheumatic Dis. 2020;79(6):819-828. doi:10.1136/annrheumdis-2019-216515

3. Kloppenburg M, Berenbaum F. Osteoarthritis year in review 2019: epidemiology and therapy. Osteoarthritis Cartilage. 2020;28(3): 242-248. doi:10.1016/j.joca.2020.01.002 
4. Berenbaum F, Blanco FJ, Guermazi A. Subcutaneous tanezumab for osteoarthritis of the hip or knee: efficacy and safety results from a 24-week randomised phase III study with a 24-week follow-up period. Ann Rheumatic Dis. 2020;79(6):800-810. doi:10.1136/ annrheumdis-2019-216296

5. Malfait AM, Miller RE, Block JA. Targeting neurotrophic factors: novel approaches to musculoskeletal pain. Pharmacol Ther 2020;211:107553. doi:10.1016/j.pharmthera.2020.107553

6. Collison J. Anti-NGF therapy improves osteoarthritis pain. Nat Rev Rheumatol. 2019;15(8):450. doi:10.1038/s41584-019-0266-y

7. Aloe L. Rita Levi-Montalcini: the discovery of nerve growth factor and modern neurobiology. Trends Cell Biol. 2004;14(7):395-399. doi:10.1016/j.tcb.2004.05.011

8. Flynn R, Chapman K, Iftinca M, Aboushousha R, Varela D, Altier C. Targeting the transient receptor potential vanilloid type 1 (TRPV1) assembly domain attenuates inflammation-induced hypersensitivity. J Biol Chem. 2014;289(24):16675-16687. doi:10.1074/jbc.M114.55 8668

9. Isola M, Ferrari V, Miolo A, et al. Nerve growth factor concentrations in the synovial fluid from healthy dogs and dogs with secondary osteoarthritis. Vet Comp Orthop Traumatol Vcot. 2011;24(4): 279-284. doi:10.3415/VCOT-10-04-0051

10. Montagnoli $\mathrm{C}$, Tiribuzi R, Crispoltoni L, et al. $\beta$-NGF and $\beta$-NGF receptor upregulation in blood and synovial fluid in osteoarthritis. Biol Chem. 2017;398(9):1045-1054. doi:10.1515/hsz-2016-0280

11. Pecchi E, Priam S, Gosset M, et al. Induction of nerve growth factor expression and release by mechanical and inflammatory stimuli in chondrocytes: possible involvement in osteoarthritis pain. Arthritis Res Ther. 2014;16(1):R16. doi:10.1186/ar4443

12. Takano S, Uchida K. Nerve growth factor regulation by TNF-alpha and IL-1beta in synovial macrophages and fibroblasts in osteoarthritic mice. J Immunol Res. 2016;2016:5706359. doi:10.1155/2016/570 6359

13. Blaney Davidson EN, van Caam AP, Vitters EL, et al. TGF-beta is a potent inducer of Nerve Growth Factor in articular cartilage via the ALK5-Smad2/3 pathway. Potential role in OA related pain? Osteoarthritis Cartilage. 2015;23(3):478-486. doi:10.1016/j.joca.20 14.12 .005

14. Iannone F, De Bari C, Dell'Accio F, et al. Increased expression of nerve growth factor (NGF) and high affinity NGF receptor (p140 TrkA) in human osteoarthritic chondrocytes. Rheumatology. 2002;41 (12):1413-1418. doi:10.1093/rheumatology/41.12.1413

15. Schnitzer TJ, Marks JA. A systematic review of the efficacy and general safety of antibodies to NGF in the treatment of OA of the hip or knee. Osteoarthritis Cartilage. 2015;23(Suppl 1):S8-S17. doi:10. 1016/j.joca.2014.10.003

16. Lane NE, Schnitzer TJ, Birbara CA, et al. Tanezumab for the treatment of pain from osteoarthritis of the knee. N Engl J Med. 2010;363 (16):1521-1531. doi:10.1056/NEJMoa0901510

17. von Loga IS, El-Turabi A, Jostins L. Active immunisation targeting nerve growth factor attenuates chronic pain behaviour in murine osteoarthritis. Ann Rheumatic Dis. 2019;78(5):672-675. doi:10.11 36/annrheumdis-2018-214489

18. Chlebowski RT, Cirillo DJ, Eaton CB, et al. Estrogen alone and joint symptoms in the Women's Health Initiative randomized trial. Menopause. 2018;25(11):1313-1320. doi:10.1097/gme.0000000000 001235

19. Helmick CG, Felson DT, Lawrence RC, et al. Estimates of the prevalence of arthritis and other rheumatic conditions in the United States. Part I. Arthritis Rheum. 2008;58(1):15-25. doi:10.1002/art.23 177

20. Strand V, McIntyre LF, Beach WR, Miller LE, Block JE. Safety and efficacy of US-approved viscosupplements for knee osteoarthritis: a systematic review and meta-analysis of randomized, saline-controlled trials. J Pain Res. 2015;8:217-228. doi:10.2147/ jpr.s 83076
21. Duan-Porter W, Goldstein KM, McDuffie JR, et al. Reporting of sex effects by systematic reviews on interventions for depression, diabetes, and chronic pain. Ann Intern Med. 2016;165(3):184-193. doi: $10.7326 / \mathrm{m} 15-2877$

22. Shivers KY, Amador N, Abrams L, Hunter D, Jenab S, QuiñonesJenab V. Estrogen alters baseline and inflammatory-induced cytokine levels independent from hypothalamic-pituitary-adrenal axis activity. Cytokine. 2015;72(2):121-129. doi:10.1016/j.cyto.2015.01.007

23. Nevitt MC, Cummings SR, Lane NE, et al. Association of estrogen replacement therapy with the risk of osteoarthritis of the hip in elderly white women. Study of Osteoporotic Fractures Research Group. Arch Intern Med. 1996;156(18):2073-2080. doi:10.1001/ archinte.1996.00440170081009

24. Sestak I, Cuzick J, Sapunar F, et al. Risk factors for joint symptoms in patients enrolled in the ATAC trial: a retrospective, exploratory analysis. Lancet Oncol. 2008;9(9):866-872. doi:10.1016/s14702045(08)70182-7

25. Wright AF, Ewart MA, Mair K, et al. Oestrogen receptor alpha in pulmonary hypertension. Cardiovasc Res. 2015;106(2):206-216. doi:10.1093/cvr/cvv106

26. Hsu I, Chuang KL, Slavin S, et al. Suppression of ERbeta signaling via ERbeta knockout or antagonist protects against bladder cancer development. Carcinogenesis. 2014;35(3):651-661. doi:10.1093/carcin/bgt348

27. Zeng K, Zhang HQ, Chen Y, Gao Q. Estradiol via estrogen receptor beta inhibits chondrogenesis of mouse vertebral growth plate in vitro. Childs Nervous Syst. 2015;32:1-5.

28. De KM, Stolk L, Zillikens MC, et al. Lower sex hormone levels are associated with more chronic musculoskeletal pain in community-dwelling elderly women. Pain. 2016;157.

29. Prieto-Alhambra D, Javaid MK, Judge A, et al. Hormone replacement therapy and mid-term implant survival following knee or hip arthroplasty for osteoarthritis: a population-based cohort study. Ann Rheum Dis. 2015;74(3):557-563. doi:10.1136/annrheumdis-2013204043

30. de Kruijf M, Stolk L, Zillikens MC, et al. Lower sex hormone levels are associated with more chronic musculoskeletal pain in community-dwelling elderly women. Pain. 2016;157(7):1425-1431. doi:10.1097/j.pain.0000000000000535

31. Bei MJ, Tian FM, Xiao YP, et al. Raloxifene retards cartilage degradation and improves subchondral bone micro-architecture in ovariectomized rats with patella baja-induced - patellofemoral joint osteoarthritis. Osteoarthritis Cartilage. 2020;28(3):344-355. doi:10. 1016/j.joca.2019.06.014

32. Driscoll C, Chanalaris A, Knights C, et al. Nociceptive sensitizers are regulated in damaged joint tissues, including articular cartilage, when osteoarthritic mice display pain behavior. Arthritis Rheumatol. 2016;68(4):857-867. doi:10.1002/art.39523

33. Yu X, Qi Y, Zhao T, et al. NGF increases FGF2 expression and promotes endothelial cell migration and tube formation through PI3K/Akt and ERK/MAPK pathways in human chondrocytes. Osteoarthritis Cartilage. 2019;27(3):526-534. doi:10.1016/j.joca.20 18.12.007

34. Gibbs RB, Wu D, Hersh LB, Pfaff DW. Effects of estrogen replacement on the relative levels of choline acetyltransferase, trkA, and nerve growth factor messenger RNAs in the basal forebrain and hippocampal formation of adult rats. Exp Neurol. 1994;129 (1):70-80. doi:10.1006/exnr.1994.1148

35. Liuzzi FJ, Scoville SA, Bufton SM. Long-term estrogen replacement coordinately decreases trkA and beta-PPT mRNA levels in dorsal root ganglion neurons. Exp Neurol. 1999;155(2):260-267. doi:10. 1006/exnr.1998.6999

36. Villalvilla A, Gomez R, Lugo L, Lopez-Oliva F, Largo R, HerreroBeaumont G. Aromatase expression in human chondrocytes: an induction due to culture. Maturitas. 2016;85:27-33. doi:10.1016/j. maturitas.2015.12.001 
37. Son YO, Chun JS. Estrogen-related receptor $\gamma$ is a novel catabolic regulator of osteoarthritis pathogenesis. BMB Rep. 2018;51 (4):165-166. doi:10.5483/bmbrep.2018.51.4.019

38. Pombosuarez M, Castañooreja MT, Calaza M, Gomezreino J, Gonzalez A. Differential upregulation of the three transforming growth factor beta isoforms in human osteoarthritic cartilage. Ann Rheum Dis. 2009;68(4):568-571. doi:10.1136/ard.2008.090217

39. van Spil WE, Szilagyi IA. Osteoarthritis year in review 2019: biomarkers (biochemical markers). Osteoarthritis Cartilage. 2020;28 (3):296-315. doi:10.1016/j.joca.2019.11.007

40. Jiang $\mathrm{Y}, \mathrm{Hu} \mathrm{C}, \mathrm{Yu} \mathrm{S}$, et al. Cartilage stem/progenitor cells are activated in osteoarthritis via interleukin-1 $\beta /$ nerve growth factor signaling. Arthritis Res Ther. 2015;17(1):1-13. doi:10.1186/s13075-0150840-x

41. Morales TI, Joyce ME, Sobel ME, Danielpour D, Roberts AB. Transforming growth factor-beta in calf articular cartilage organ cultures: synthesis and distribution. Arch Biochem Biophys. 1991;288(2):397-405. doi:10.1016/0003-9861(91)90212-2
42. Lisi S, Sisto M, Ribatti D, et al. Chronic inflammation enhances NGF-beta/TrkA system expression via EGFR/MEK/ERK pathway activation in Sjogren's syndrome. Journal of Molecular Medicine. 2014;92(5):523-537. doi:10.1007/s00109-014-1130-9

43. Gibbs RB, Wu D, Hersh LB, Pfaff DW. Effects of estrogen replacement on the relative levels of choline acetyltransferase, trkA, and nerve growth factor messenger RNAs in the basal forebrain and hippocampal formation of adult rats. Exp Neurol. 1994;129 (1):70-80. doi:10.1006/exnr.1994.1148

44. Kaur G, Janik J, Isaacson LG, Callahan P. Estrogen regulation of neurotrophin expression in sympathetic neurons and vascular targets. Brain Res. 2007;1139:6-14. doi:10.1016/j.brainres.2006.12.084

45. Craft RM. Modulation of pain by estrogens. Pain. 2007;132(Suppl 1):S3-S12. doi:10.1016/j.pain.2007.09.028

46. Liang Y, Xie H, Wu J, Liu D, Yao S. Villainous role of estrogen in macrophage-nerve interaction in endometriosis. Reprod Biol Endocrinol. 2018;16(1):122. doi:10.1186/s12958-018-0441-z

\section{Publish your work in this journal}

The Journal of Pain Research is an international, peer reviewed, open access, online journal that welcomes laboratory and clinical findings in the fields of pain research and the prevention and management of pain. Original research, reviews, symposium reports, hypothesis formation and commentaries are all considered for publication. The manuscript management system is completely online and includes a very quick and fair peer-review system, which is all easy to use. Visit http:// www.dovepress.com/testimonials.php to read real quotes from published authors. 